\title{
LOS VIDEOJUEGOS Y SU PERCEPCIÓN HISTÓRICA SOBRE LAS GUERRAS DEL SIGLO XX'
}

\author{
Carlos DE LA CRUZ VILLANUEVA \\ Universidad Ricardo Palma \\ carlos.delacruz@urp.edu.pe
}

\begin{abstract}
"Ese día, él murió, era pequeño y solo pensaba, que él ya no estaría, quién me contaría historias, ya no caminaría de su mano y lo acompañaría en sus vivencias como abuelo. En el velorio estaba solo, en mi cabeza solo recordaba los tiempos en que él estaba. Los meses pasaron y mi abuela, mi madre y mi hermano estuvieron allí, pero también las películas. Años más tarde el dolor y la perdida tocaron la puerta en la navidad. Esa tarde, ella murió, ya no estaría la que me protegía y me animaba en hacer y vivir, mi abuela ya no estaría en la noche de navidad, la soledad regreso, esa noche del velatorio, en el dolor y asilamiento me acompaño irónicamente una consola de videojuegos Ilamada Atari. Nunca la remplazo, solo me ayudo a que su partida sea menos dolorosa, la había comprado mi abuela, pues recordaba, como me protegió del castigo de mi madre al saber que jugaba en las máquinas de juegos, sea como sea, ese iba a ser mi regalo, para ya no ir a los salones de juegos y estar en casa. Esa fue mi primera consola de juegos de video, luego vinieron otras y hasta la fecha son parte de mi hacer cotidiano." Mi primera consola de videojuegos. (Notas y recuerdos personales). CADV (enero $22 \mathrm{de}$ 2018)
\end{abstract}

hacer de un pasatiempo, una investigación fue muy difícil, ipor supuesto que lo sé! Pero tenía que hacerlo, y nunca lo hubiese logrado, sin la familia, maestros y amistades.Gracias a Tod@s.

\section{RESUMEN}

La siguiente investigación es el inicio de un trabajo de mayor envergadura, desarrollado bajo la narrativa del ensayo, tiene como objetivo identificar los aspectos más relevantes de los videojuegos orientados a recrear eventos bélicos de gran importancia histórica, como son las guerras mundiales. Entre los aspectos más notables, que esta investigación ofrece, es la identificación y delimitación de posibles linderos, para el análisis a los videojuegos. Considerándolos como fuentes históricas, pues siendo creaciones sociales, recrean y generan una percepción a situaciones u hechos de la realidad, bajo el velo de la diversión, recreación, entretenimiento y fantasía.

1 Las primeras ideas sobre esta investigación, pude exponerlas en el VII Encuentro de jóvenes investigadoras e investigadores de historia contemporánea. Desarrollado en la Universidad de Granada en España, representado en calidad de docente investigador a la Universidad Ricardo Palma y la UNMSM, en septiembre de 2019. Este ensayo lleva el mismo título, siendo estas páginas, orientadas a presentar elementos anteriores y otros aspectos, pero la esencia, pudo ver las primeras luces, en la difusión histórica en dicho coloquio, en donde se pudo enriquecer con las diversas apreciaciones, orientaciones, sobre todo con los consejos, opiniones y preguntas, gestadas por historiadores y jóvenes historiadores españoles, en las mesas taller del encuentro de investigadores. 
En estas páginas, nos acercaremos, a los alcances y limitaciones del estudio a los videojuegos, mediante la breve observación de tres de ellos, que ambientan o recrean algunos momentos de las guerras de las guerras en el siglo XX. Mediante ello observaremos su utilidad, como fuente, complemento y entendimiento, que la industria videojueguil, crea, recrea y reflexiona con respecto a las guerras en el siglo XX. Ello gracias a la exploración inicial desde la mirada del historiador.

\section{PALABRAS CLAVE}

Historia y videojuegos, utilidad y reflexión sobre los videojuegos, los videojuegos y su impacto en la Historia, los videojuegos como fuente histórica.

\section{VIDEOGAMES AND THEIR HISTORICAL PERCEPTION ON THE WARS OF THE 2OTH CENTURY}

\section{SUMMARY}

The following research is the beginning of a larger work, developed under the narrative of the essay, aims to identify the most relevant aspects of video games aimed at recreating warlike events of great historical importance, such as world wars. Among the most notable aspects that this research offers is the identification and delimitation of possible boundaries for the analysis of video games. Considering them as historical sources, since they are social creations, they recreate and generate a perception of situations or facts of reality, under the veil of fun, recreation, entertainment and fantasy.

In these pages, we will approach the scope and limitations of the study of video games, through the brief observation of three of them, which set or recreate some moments of the wars of wars in the twentieth century. Through this we will observe its usefulness as a source, complement and understanding that the video industry jueguil, creates, recreates and reflects on wars in the twentieth century. This is thanks to the initial exploration from the perspective of the historian.

\section{KEYWORDS}

History and video games, use and reflection into video games, video games and their impact on history, video games as a historical source.

Recibido: 27/03/2020

Aprobado:29/05/2020 


\section{POR QUÉ OBSERVAR AL VIDEOJUEGO}

$\mathrm{E}$

scribir sobre la relación existente entre los videojuegos y la historia, es iniciar un recorrido intelectual a un universo dinámico, creativo y que con el pasar de los años a formado parte del entretenimiento de la cotidianidad del mundo. Esta producción cultural, orientada al entretenimiento, se constituye como todo un fenómeno cultural, por su impacto, extensión, difusión, elaboración y por su adaptación social, que se evidencia en el tiempo. Las siguientes páginas ofrecen al lector una observación a diversos puntos de interés u orientación, en nuestra labor como historiadores, que no excluye a investigadores de otras tribunas, ni mucho menos a fanáticos o interesados en el mundo videojueguil.

En principio para abordar este fenómeno, es necesario conocerlos y haber experimentado con ellos, pues a partir de esta experiencia, podremos ver diversas aristas, que son parte de ese mundo. Y que inicialmente nos permiten evidenciar dos relaciones. La primera, es que este ingreso inicial por parte del observador del fenómeno, genera un vínculo de aprendizaje y experiencia, con su materia de investigación, todo bajo el velo del entretenimiento. La segunda relación, es que mediante este ingreso el investigador, en este caso el historiador, encontrará o decodificará inicialmente la dinámica social, la composición o los elementos que componen la comprensión de fenómenos sociales en el tiempo, además de ello, serian de gran ayuda en el desarrollo historiográfico.

Cuando el investigador ingresa a este terreno, no solo experimenta con juegos de video, se hace parte de una población, que, mediante el videojuego, se entretiene, divierte, o simplemente le interesa algo de este espacio. Es decir, su vínculo va más allá de la observación, lo hace participe y miembro de una comunidad, no solo imaginada, sino real que ve, en los juegos de video, no solo una expresión social, los siente como parte de su quehacer cotidiano. Lo cual hace posible comprender múltiples aspectos como: grupos y subgrupos, intereses, afinidades, el lenguaje, algunos efectos, tipos, formas, variedad, entre otros expresiones u elementos. En síntesis, múltiple información y contenidos, entre otros elementos, que lo pone en ventaja, sobre otros investigadores no habituados a este mundo. Pero también, a parte de poseer esa ventaja, puede comprender a la comunidad y la expresión social que generan los juegos en la sociedad. Pero a pesar de lo atractivo que puede ser este mundo, es visto por diversos espacios de las ciencias sociales, en nuestras fronteras, como solo una entidad de entretenimiento y por lo tanto la exclusión o marginalidad, lo colocan en los temas de investigación extremas, modismos o anecdóticas investigaciones.

Si optamos por otra postura, podremos orientar a este tipo de investigaciones en los linderos de los estudios históricos especializados como: Las mentalidades, lo imaginario, lo cultural o lo material. Lo cierto es que este tipo de temáticas rejuvenecen en general nuestras fronteras de investigación, pues renuevan y obligan en ampliar, nuestros horizontes, conocimientos, metodologías, técnicas, instrumentos, pero sobre todo ampliar nuestras fuentes de información e investigación, ámbitos de interacción, herramientas metodológicas y teóricas, 
pues esta comprensión inicial, de nuestra generación, trazara la trayectoria con respecto al desarrollo de otras investigaciones, que seguirán las próximas generaciones y otorgaran, tal vez, de mayor madurez el trabajo intelectual, con respecto a las producciones sociales.

Nuestro ensayo u avance de investigación, tiene como principal intención un acercamiento histórico en delimitar y organizar algunas ideas, referidas al estudio de los videojuegos bajo la perspectiva histórica, para así lograr comprender como estos ingresan e influencian en el imaginario colectivo haciendo uso del pasado social, el cual conforma parte de nuestra vida cotidiana, como atractivo para sus tramas. Y mediante esta elaboración se reintegra y recompone en la sociedad, constituyendo al juego de video con trama histórica, como un nuevo soporte de información social, que descompone el pasado, lo reutiliza y mediante ello interviene en el imaginario y la vida cotidiana, por medio del uso del pasado, o siendo más precisos, acontecimientos o momentos históricos pasados, que son atractivos para la industria del videojuego, por su complejidad, composición social y porque son parte de la memoria social colectiva.

Luego de esta breve postura con respecto a sujeto y objeto de investigación. Debemos, continuar nuestro camino, elaborando una descripción conceptual, sobre el objeto material de la investigación, la cual sea de utilidad en nuestra apreciación intelectual, además pueda versar sobre lo que son los videojuegos, su naturaleza, impacto y aprecio sociocultural. Entonces debemos concebir a los juegos de video, como creaciones sociales, que poseen historia e influencian socialmente a las colectividades, y con el tiempo se han convertido en elementos que contienen o complementan nuestra memoria colectiva, pues albergan información, no solo de su creación, también porque pueden ser producto intencional, tal como sucede con los juegos que son elaborados para reproducir u adecuar eventos históricos, cuyo principal interés es entretener al público interesado en el pasado y a su vez económicamente mantener y desarrollar a la industria en general orientada y derivada de este medio. Pero también como toda creación, bajo la perspectiva hermenéutica, poseen información que se constituirá en parte de nuestra vida y por lo tanto en memoria, pues al recrear fenómenos históricos, se constituyen en nuevos receptáculos que albergan información, parte de nuestra memoria colectiva, que puede complementar nuestra información con respecto a algunos acontecimientos u fenómenos históricos.

Además, pretendemos señalar, por medio de una descripción en base a nuestra experiencia, alguna posibilidad de abordar metodológicamente y reflexionar sobre el tratamiento de estas fuentes, para desarrollar temas investigación histórica y la apertura de nuestras fronteras de investigación. Esta aproximación descriptiva conceptual, nos permite también plantearnos algunas interrogantes, que cualquier investigador social, cuando ingresa a estos temas, se plantea inicialmente: ¿Por qué abordar este tema? ¿Cómo se debe investigar? Y sobre todo ¿Cuál será la utilidad?, estas interrogantes son las coordenadas iniciales, que nos permiten, no solo explorar en la bibliografía preliminar, nos generaran una dirección y la razón para abordar el tema y experimentar, empírica y metodológicamente al videojuego. 


\section{QUÉ ES EL VIDEOJUEGO PARA LA INVESTIGACIÓN HISTÓRICA}

Qué es un juego, es una creación social orientada al entretenimiento, el aprendizaje y adiestramiento, que, a través del tiempo, se ha ido construyendo, adecuando al contexto y a diversas actividades de la vida. Una aproximación histórico cultural a esta creación material, la desarrolla en el Homo Ludens, J. Huizinga ${ }^{2}$, (2007) el cual historiográficamente, es uno de los grandes tópicos, para el estudio del juego, su aporte, para el siglo XX, no solo radica en una análisis innovador para su tiempo, es además uno de los estudios en perspectiva histórica y cultural, que nos permiten apreciar al juego como una creación cultural que aborda, responde, rememora y vincula a los individuos en sociedad, explora al juego, su impacto, necesidad y utilidad. Gracias a su aporte, en la actualidad comprendemos al juego, como una construcción cultural, que históricamente se ha podido adaptar y complejizar en el tiempo, también el juego como tal a podido constituirse como una actividad de entretenimiento, pero que en su interior cumple múltiples funciones como informar, educar, entrenar y prepararse para otros tiempos o momentos, es una actividad que en el devenir, ha experimentado diversos cambios, de acuerdo a múltiples las necesidades e intercambios culturales, lo que ha generado su adaptación, hasta ser parte de nuestras vidas. Si comprendemos al juego como un constructo social, sabremos que responde a diversas necesidades o improntas, pero también debemos tomar en cuenta que; adiestra al individuo en ciertos aspectos o lo prepara para ciertas circunstancias. Sin olvidar lo dinámico y fantástico que recrea e influencia en el individuo y por ende a la colectividad que lo experimenta. pues no solo ejercita parte de nuestro cuerpo y mente, a la vez, el juego sirve para entretener mediante la experimentación simulada alguna de las acciones o situaciones sociales generadas por la humanidad.

Iniciar en la comprensión del juego, es un paso preliminar y obligatorio, pues al ser parte de un constructo cultural se ha adaptado en el tiempo histórico, integrando diversos medios, formatos u formas, una de ellas es el videojuego, el cual es, toda una elaboración sofisticada y tecnológicamente actualizada a nuestra contemporaneidad del juego, el cual tiene como objetivo entretener, mediante la competitividad y el reto, a su usuario. Esta Construcción material u expresión cultural correspondiente a la segunda mitad del siglo XX y que a nuestros días, se ha convertido en parte de nuestra vida cotidiana, es una muestra de la capacidad dinámica de adaptación de las creaciones sociales como el juego, a los nuevos tiempos y producto de ello, innovo nuestra forma de ver al juego, pues entrelazo tecnología informática con el adiestramiento, entretenimiento, la imaginación y creatividad, generando así lo que hoy entendemos como videojuegos, juegos de video, recreaciones informáticas o videogames.

2 Véase. Huizinga, JOHAN. Homo Ludens. España. Alianza Editorial. 2007 (1938). Págs. 11 - 65. es sabido que existen otros trabajos que actualizan el tema del juego en la historia, como el de Botermans, JACK, Y Varios Autores. El Libro de los Juegos. Historia y origen de los Juegos. España. Editorial P\&J. 1987 Y en específico para los videojuegos es recomendable los textos de: Kent, STEVEN L., La Gran Historia de los Video Juegos. Nova. 2011. Y el trabajo de: Lebihan, YANN. La historia de los Videojuegos. España. Ma Non Tropo. 2018. Pero en lo referido al juego, el análisis de Huizinga, es hasta la fecha un buen punto de inicio, para comprender dentro de los aspectos de la historia cultural al juego, su reelaboración e impacto en el desarrollo de la civilización. 
Ya en el siglo XXI, la historia, ha ingresado a comprender el horizonte del videojuego desde su origen, expresiones, formas, impacto y utilidad. Enriqueciendo el conocimiento sobre ello, Pues como es sabido la Historia, cumple una vital labor, por su capacidad en la comprensión de la sociedad a través del tiempo, siendo esta, la que nos permitiría comprender los cambios y sobre todo la utilidad generada en el tiempo. además de brindarnos una reflexión e innovación en nuestro quehacer, una situación que se convierte en un reto metodológico, teórico e historiográfico, en diversas partes del mundo. Pues referirnos a los videojuegos en otras realidades sociales, en los círculos de investigación, son situaciones de gran interés, pues es innegable su presencia por razones como: las económicas, políticas, sociales, culturales y porque ocupan un gran espacio en la vida cotidiana.

En los últimos años escribir sobre los videojuegos, en los círculos de las ciencias sociales y en particular en la historia, es algo innovador en diversas partes del mundo, pero este sentir, no es similar en nuestras fronteras, siendo esto de muy lento avance en Latinoamérica. Principalmente en el Perú, ello por múltiples razones contextuales y coyunturales como: Porque historiográficamente, analizar dichas construcciones sociales y reflexionar sobre ellas, es considerado una temática irrelevante, un modismo, e incluso podría ser considerado como parte de un quehacer posmodernista, etc. Sea como se catalogue, este tipo de análisis es considerado, como una temática de escaza seriedad, pues aún, se les ve como, un mero medio de entretenimiento y por lo tanto labor de otras ciencias. Además de que la comunidad científica, por nuestro contexto, se concentra en problemáticas de mayor interés social, que nos ayuden a comprender; continuidades, contracciones, acontecimientos y diversos dilemas como: La corrupción, el cual es un flagelo que ha golpeado enormemente la formación de nuestro Estado, la reflexión entrono a nuestra independencia, próxima a cumplir 200 años de elaboración, retrotrayendo reflexiones como; la formación del Estado, los militarismos, la ciudadanía, la gobernabilidad e institucionalidad. Además, que en nuestro tiempo, el crecimiento económico, no solo ha dado pie a comentar sobre el mismo, sus condiciones y elementos, particularidades y logros, también se nos han presentado flagelos como; la pobreza, la inseguridad ciudadana, la marginalidad, la ciudadanía, la migración, la institucionalidad, etc, Problemáticas que son parte de nuestro día a día en nuestro Perú.

Por ello temas como el que se abordan en estas páginas, son poco evaluados, pero si lo vemos en otra perspectiva, este momento es adecuado para ingresar a comprender el universo videojueguil, pues se nos presenta como un respiro intelectual, el cual innova y corresponde a experimentar nuevos enfoques $u$ especialidades, gracias a ello en la actualidad la historia considera principalmente a los videojuegos como una construcción cultural, que debe ser observada en forma específica, como un elemento social, el cual nos expresa o revela un aspecto de nuestra realidad y/o cultura material. El cual, se ha expuesto como parte de debates o reflexiones mediáticas e incluso considerado como un problema social, e inclusive su aparición y desarrollo es satanizado y desprestigiado vinculando al producto con alguna patología psicológica como; incitación a la criminalidad, vicio, aislamiento social, trastorno, ludopatía, entre otros dilemas sociales. Donde 
la opinión es muy dividida entre especialistas en el tema, circunstancia que también dificulta la investigación, en nuestras fronteras y que amplía los dilemas económicos e intelectuales, para desarrollar estas investigaciones.

La solución historiográfica, ante este dilema muy contemporáneo, en nuestra realidad coyuntural y contextual peruana, es iniciar el camino, a pesar de lo riesgoso, en la comprensión desde la perspectiva histórica a los videojuegos, considerarlos no solo como una expresión social, que nos evidencia una multiplicidad de manifestaciones. Además, apreciar al juego de video, como una entidad que posee toda una relevancia que debemos, los científicos sociales, decodificar y a partir de ello explorar su complejidad, mediante los estudios históricos referidos, a las manifestaciones y creaciones culturales. Logrando así ampliar nuestra madurez intelectual, innovar elementos teóricos y metodológicos para su estudio, conocimiento y comprensión.

Pero debemos también considerar, que el desarrollar este tipo de trabajos expondrá sus propios dilemas; desde fragilidad, desinterés e incluso marginalidad intelectual. Aunque con el pasar de los años, en este lado del mundo, se oriente su conocimiento a la descripción y ocasional mención, ello puede darnos cierto aliento a la relevancia u interés social, que con el tiempo se están dando en medios de comunicación en nuestra televisión peruana con programas como $\mathrm{TEC}^{3}$, difundidos en WEB y transmitidos por el Canal 4, en el cual desde el 2012 y con pocos años de trabajo continuo, informan de novedades y realizaciones tecnológicas y sobre el ámbito de los videojuegos, además de espacios reconocidos en redes sociales como Facebook y YouTube a personalidades como Phillip Chu Joy ${ }^{4}$, el cual siempre ofrece en sus medios y en televisión peruana, la descripción, orientación e información, sobre la tecnología, el desarrollo, los alcances técnicos e innovaciones de este mundo del videojuego y como son parte de nuestra vida cotidiana. Pero estos espacios como otros son de gran capacidad informativa, informática e influencia social cultural y comercial, aun no son suficientes, para cautivar en forma constante en la investigación histórica peruana, dejando a estas exploraciones en meros constructos anecdóticos, informativos orientados solo al que hacer tecno informático.

Y como agregue en líneas anteriores la labor de los historiadores en el Perú, principalmente gira en torno a el análisis de hechos de mayor complejidad, a pesar de que, todo lo que nos rodea posee importancia y complejidad. Por ello en nuestra búsqueda de respuestas, sobre el pasado y presente, debemos concentrarnos primordialmente a observar toda una gran diversidad de dificultades y contracciones sociales, cuyas respuestas contribuyan a construir el presente y nuestro futuro. Gracias a ese ideal ampliamos el conocimiento y reflexión sobre nuestro ser social, lo cual es nuestro deber, e ingresar a comprender dichas magnitudes que se despliegan en la sociedad. En donde el estudio referido a los videojuegos será apreciado, temporalmente, como una moda o desvío intelectual intencional, para refrescar nuestra actividad histórica, que cobrará importancia en nuestro país con el pasar de los años.

3 Véase https://www.youtube.com/channel/UCBtSfnUVAuq9fKaPrMWa_ag.

4 Véase https://www.youtube.com/channel/UCym16Z6ocsTe85tz91eyl4w 
El estudiar históricamente a los videojuegos, no solo es una nueva apertura historiográfica pasajera o de moda, es un giro que nos brinda nuevos espacios que también innoven en nuestra labor, pero que, por ahora serán incomprendidos o poco valorados, por nuestro contexto. Pero es importante arriesgarnos, porque nos permite correr el velo y observar de la realidad, parte de su elaboración cultural, que apertura múltiples manifestaciones y nos sumerge en una dinámica muy compleja, que desarrolla e influencia a la colectividad en el tiempo y espacio. Básicamente realizar investigaciones sobre el impacto social de los juegos de video en la sociedad, es un terreno de gran complejidad, pues desde las últimas tres décadas del siglo XX y nuestro actual siglo XXI, ese impacto se ha incrementado, por su difusión y conexión generacional. Además, se ha diversificado, el impacto social, lo que ha generado problemáticas o alcances, ello se puede evidenciar por el interés con respecto a analizarlos desde los múltiples ámbitos que van desde; la salud, la economía, la política, el arte, la ciencia, etc.

Ello nos ha propuesto diversas preguntas y respuestas, recurrentes, sobre los usos y manifestaciones que han generado los videojuegos, lo cual es positivo, pues entrega a la historia una oportunidad para ampliar su espectro de acción y apertura un nuevo interés a nuestro quehacer e incluso, genera un nuevo camino metodológico al poder utilizar una y más fuentes para la observación y comprensión sobre las sociedades a través del tiempo. Pero debemos tomar en cuenta que ello traería como efecto una nueva especialización, como lo que a sucedido, en el terreno de lo audio visual, con el cine y la televisión, en la investigación en las ciencias sociales ${ }^{5}$.

Además de que directamente como temática pasaría a conformar los intereses de investigación, de las especializaciones ya consagradas de la historia como; social, cultural, simbólica, artística, de lo imaginario, lo micro histórico, entre otras. Ello permitiría al historiador ingresar a las nuevas fuentes y analizarlas bajo su estilo, para lo cual deberá acoplar, integrar o innovar en nuevas técnicas, pues tendrá que observar e interactuar con los videojuegos y con todo ello, que haría posible ingresar a su mundo, al menos en forma referencial, como por ejemplo conocer sus tipos, formas, estilos, lenguaje, despliegue gráfico, tramas, principales empresas, dispositivos, ventajas, desventajas, evolución, consolas, lugares, encuentros o certámenes internacionales, entre otros elementos parte de su desarrollo y despliegue cultural ${ }^{6}$. Además, tomando en cuenta no solo su jugabilidad, tendrá que fijarse en el interés e impacto social y para ello deberá de crear instrumentos de complejidad e incluso observar espacios de interés, virtuales, lo cual lo orientaría a observar espacios como; foros virtuales, canales de YouTube, sitios especializados, consultar a casas de venta, entre otras. Estos elementos señalados, serian fronteras y linderos de ingreso a un mundo de gran complejidad, el cual, con nuestras habilidades como historiadores, se vería

5 Véase dos textos de gran interés para comprender los alcances de estos dos fenómenos sociales. Ferro, MARC. El cine. Una visión de la Historia. España. Akal. 2008 y Bourdieu, PIERRE. Sobre la Televisión. Barcelona. Anagrama. 1996.

6 Véase los siguientes documentales y reportajes https://www.youtube.com/watch?v=fdzizl3MEUs\&t=4576s / https://www.youtube.com/watch?v=|06X1nZuAOc\&t=46s/https://www.youtube.com/watch?v=rAbpF6XqIAM 
enriquecido ${ }^{7}$, como ya se puede ver en otros lados del mundo, en donde la historia se ha integrado a múltiples ciencias y conocimientos para comprender una diversidad de fenómenos sociales en el tiempo.

\section{EL VIDEOJUEGO, UNA DESCRIPCIÓN DE SU DESARROLLO Y SUS ALCANCES}

Un videojuego es una creación cultural, desarrollada por una diversidad de empresas orientadas a ello, este constructo cultural genera en los video jugadores una experiencia neuromotora compleja ${ }^{8}$, la cual produce en el individuo una inmersión a una recreación ficticia, que lo entretiene, complejiza y divierte, mediante el uso de una gran diversidad de recursos como; el fotorealismo, lo sonoro, lo argumentativo, entre otros. El cual entremezcla lo real y lo fantástico, generando una distopía, de un gran contenido y despliegue, que estimulan al usuario y a todos aquellos que entren u estén en contacto con esa creación. Cuya principal finalidad es la diversión y/o entretenimiento de un individuo o grupo, ya sea presencial o virtual. Estas creaciones orientadas a la diversión han integrado generaciones y fueron ganando desde las últimas tres décadas del siglo XX y hasta la actualidad, un espacio en el estilo de vida de niños, jóvenes, adultos y adultos mayores.

El videojuego ha recorrido muchas décadas desde los espacios dedicados a la experimentación táctica o pasatiempos intelectuales como: "XOX" (1952) o el "Tennis for two" (1958), ya a mediados de los 60 los juegos como "Spacewar" (1962), fueron parte de la vida ingeniera universitaria norteamericana, un momento donde lo lúdico e intelectual se daban la mano, no dejando de lado los símiles japoneses en los centros tecnológicos, que veían con asombro dichas creaciones. Situación que años más tarde permitió a empresas como Taito en los 70 tomen el espacio de los video juegos y compitan con la norteamericana Atari. Es en estas décadas en las cuales los videojuegos eran parte de una serie de elementos de estímulo lógico matemático de entrenamiento u adiestramiento, en diversas partes del mundo, con el pasar de los años 70' pasaron a ser parte de la cultura popular del entretenimiento.

Tras intensificarse la Guerra Fría en la década de los 70, la revolución tecnoelectroinformática genera todo un avance en los videojuegos, surgen empresarios y empresas orientadas a este rubro que masifican su uso y variedad, así fue iniciando su popularización, la llegada de "Pong", las salas de juego conocidas como ARCADE, Taito, Atari y las consolas para hogar, fue el universo que marca el termino de los años anteriores y constituyen el universo videojueguil hasta los 90. Este periodo en cuestión va consolidar una industria millonaria que determina el quehacer económico de múltiples sociedades, que en la actualidad poseen una enorme y millonaria rentabilidad, puestos de trabajo, además de ser

7 En referencia a esta idea, he tenido la posibilidad de exponer algunas ideas de los videojuegos en el Perú, su impacto y sobre todo el potencial de la observación histórica en este tipo de investigaciones, en el "IX seminario Visiones del Perú. El Perú y en el Mundo" Desarrollarlo en la universidad Ricardo Palma, en noviembre de 2019. Con la ponencia "El Perú en el mundo de los videojuegos. Observación a partir de la mirada de la Historia"

8 Véase la exposición de Daphne Bavelier https://www.youtube.com/watch?v=e_pYROUysDM 
parte de la vida de la población de aquel periodo. Desarrollando con el tiempo múltiples intereses como: el entretenimiento, la táctica y la diversidad, además de ello, fue imponiéndose y generándose opiniones divididas, comprendiendo a los videojuegos como entretenimiento u adicción. Constituyendo en consecuencias una serie de normas, lineamientos clasificaciones, censura generando en la población múltiples opiniones generando la modificación en el accionar de esta industria y constantes adaptaciones y reacciones en el tiempo.

Estas décadas nos brindaran diversiones icónicas como: Pac-Man, Galaga, Space invaders, Super Mario Bross, Sonic, Street figther, Mortal Kombat, KOF, Red Alert, Metal Gear, Resident Evil, entre otros títulos, que en pocas décadas, harán que los usuarios de los videojuegos ingresen a fantásticas realidades tecnológicamente diseñadas, en donde las tramas, retos, desafíos, competencias, simuladores de conducción de diversos vehículos, juegos de rol RPG (Rol Plaiying game), peleas, deportes, espionaje, estrategia de guerra, sociedades post apocalípticas, entre otros. Estas ingenierías en todas estas décadas de desarrollo han generado como consecuencia un ingreso al universo de la competitividad y la multitemática, por medio de recreaciones fantásticas cada vez más realistas, dinámicas y complejas, consolidando su presencia en el siglo XXI, en las diversas sociedades y culturas, siendo motivo económico de múltiples imperios empresariales, generador de billones en inversiones y rentabilidad mundial, un vehículo indudable de empleos y desarrollo tecnológico. Además de ser usado ya no solo para el entretenimiento principalmente, también en la medicina, el arte e incluso la educación.

\section{LA HISTORIA Y LOS VIDEOJUEGOS, PROPUESTA, LIMITACIONESY REFLEXIONES}

Esta investigación nos ha enfrentado a un variado universo de información, orientada principalmente a explorar temáticas como; origen, evolución tecnológica, utilidad, problemática, entre otras variantes. Pero no existe, hasta la fecha, un apartado abocado a lo teórico u metodológico, sobre como los videojuegos aportan al conocimiento histórico y no a la materia histórica u expresión histórica. Para poder contribuir a este terreno debemos basarnos en el análisis que realizamos a las creaciones materiales, a partir de la visión de nuestras fronteras, lo que nos lleva al hecho, como historiadores, de comprender a los videojuegos como elementos generados e innovados en el tiempo, que a su vez expresan inquietudes, dilemas y surrealismos de acuerdo con cada tiempo o momento. Ellos componen o integran la vida cotidiana, desarrollando y estimulando a parte de nuestro imaginario colectivo y por lo tanto la realidad social. El comprender al videojuego en el terreno del conocimiento histórico, es orientar y focalizar nuestro interés, lo que se conoce como delimitación del problema, orientada en específico a comprender como el videojuego que recrea eventos históricos, se va configurando en un nuevo soporte de memoria, sobre fenómenos sociales, influyendo así en el imaginario y la mentalidad, a través de la recreación del pasado, sin dejar de lado lo subjetivos, distopicos y complejos que son dichas creaciones. 
En este sentido los videogames al ser considerados como fuentes históricas, son apreciados para estudiar no solo su naturaleza, también son de vital importancia para evaluar sus efectos en la sociedad. Y en el caso, en que estos se abocan a la recreación de eventos históricos, se les puede analizar como un nuevo soporte de información, para nuevas y vigentes generaciones, que complementan sus conocimientos, referentes a temas u acontecimientos históricos, gracias este acercamiento a los juegos de video, la historia, no solo cumpliría con el objetivo, de comprender el desarrollo y el cambio que experimentan las sociedades en el tiempo y el espacio, mediante el análisis de las producciones materiales y su impacto en la sociedad. Además, amplificara sus horizontes teóricos metodológicos, orientándose a observar como fuentes y soportes de información de la memoria de la sociedad, para lo cual desplegara una serie de capacidades técnicas, metodológicas y teóricas, destinadas a ese fin.

A su vez historiográficamente consolidaríamos la presencia para describir y comprender cualquier fenómeno social, desarrollando una diversidad de caminos y uso de múltiples fuentes para lograr ello, tales como; lo oral, lo escrito, monumental, pictórico y lo audiovisual, para el caso del ultimo, extenderíamos nuestro universo de soportes. Tal como ha pasado con los diversas fuentes o soportes como; lo sonoro, la televisión, el cine, los documentales y ahora los videojuegos. No solo por el hecho de creación o trayectoria en el tiempo, sobre todo por ser un recipiente de información, cuando aborda fenómenos históricos en sus creaciones.

Pero debemos saber que, el videojuego que recrea sucesos, acontecimientos u ambientaciones históricas, en su naturaleza alberga un dilema complejo, su intencionalidad, es decir para la cual son creados. Si partimos del hecho ideal, que sirven para rememorar y reflexionar sobre momentos históricos, no estaríamos fuera de ese pensamiento, pero también debemos considerar que, el videojuego que recrea acontecimientos u aborda temáticas históricas, no son solo motivado por el anhelo intelectual o social, muchas de estas creaciones son desarrolladas por diversos fines como; conmemoraciones a sucesos históricos, complementación educativa, situaciones políticas, entre otros. Pero además de ello, es lo económico, pues la industria del videojuego encuentra en la recreación de sucesos del pasado, su mina de oro, pues el pasado histórico de la civilización, es atractivo para una porción de la sociedad, pues este, entremezcla, memoria, vínculos, identidad, situaciones sensibles, entre otros elementos. Los cuales, entrelazados con la diversión y entretenimiento, generan una combinación muy compleja, estimulante, atractiva, pero sobre todo rentable. Es decir, algunos videojuegos que abordan temas históricos, son desarrollados por la industria del videojuego, porque van a ser consumidos por una gran porción de la sociedad, pues estos activan en ella, su lado sensible, su memoria colectiva y su imaginario referido a estos eventos. Cumpliendo la utilidad económica para la industria y en el ámbito social, el complemento de retroalimentación del pasado.

En los últimos años, la elaboración de este tipo de creaciones que abordan hechos o momentos históricos, de gran impacto universal, han sido muy frecuentes, como es el caso de las guerras en el siglo XX. Estos episodios de conflictos bélicos, de 
nuestra historia de la civilización, cargados de sentimientos encontrados como; dolor, nostalgia, sensibilidad social, violencia y reflexión social, entre otros. Son una enorme veta, que genera una gran rentabilidad. Siendo un gran reto para la industria del videojuego, no solo ambientar o recrear la guerra, es también explorarla, describirla y hacerla un aprendizaje maduro y a su vez entretenido, sin desproporcionar el entendimiento sobre lo que es la guerra, la cual es entendida como un conflicto expansivo entre dos voluntades opuestas, que entran en un problema desmedido y desbordado de violencia, cuyo principal objetivo es la conquista de un bando sobre otro. Dicho fenómeno histórico se ha desarrollado en la humanidad a través de su historia y ha sido tratado y desarrollado desde diversos ángulos $u$ enfoques y descrito sobre diversos soportes, sean estos; diarios, textos, noticias, filmes y desde hace unas décadas los videojuegos.

La guerra es, un gran mecanismo expansivo que a través de nuestra historia ha generado diversos impactos desde; lo económico, político, social y cultural. Y gracias a los estudios históricos, a podido ser descompuesta, analizada, descrita y reflexionada. No solo mostrando razones, innovaciones y elaboraciones adelantadas a su tiempo, la investigación histórica ha podido retratar la miseria y crueldad del ser humano en aras de la expansión, el dominio y el poder. Este terreno y temática de vital interés social, ha sido y tiene, una importancia capital para toda la sociedad, pero en particular para cualquier tipo de industria, en el caso de la videojueguil, La guerra ha hecho posible el desarrollo de múltiples producciones, que podríamos decir supera o está a la par, del cine y la televisión, convirtiendo al juego de video histórico bélico, en un nuevo soporte de memoria, que en muchas ocasiones derriban la cuarta pared y mediante ello, depositan diversas interpretaciones, recreaciones subjetivas y fantásticas creaciones, inspiradas sobre la realidad y que a su vez se constituyen en nuevos elementos influenciadores de nuestra sociedad.

En nuestra investigación nos percatamos que el horizonte es muy amplio, pues los juegos que abordan el tema de la guerra, son muy numerosos, además de estar ambientados en diversos periodos u etapas de la historia de la civilización. Pero también en este proceso de selección se debe de tomar en cuenta, el estilo de juego, forma y plataforma a la cual estaban orientados, tecnología de desarrollo y consola de reproducción. Generando como resultado una selección preliminar de los juegos que abordan la temática de las guerras y para ello, tuvimos que realizar una exploración y experimentación con ellos, lo cual trajo como consecuencia una inversión económica, informaciones, opiniones y de horas de juego, para determinar cuáles serían apropiados para poder efectuar nuestra investigación. Esta selección no niega la importancia de los videojuegos, no abordados en estas páginas, que serán motivo de otras, lo cierto es que, para esta selección y clasificación, fueron de vital ayuda elementos como; la web para la búsqueda, las opiniones en YouTube, espacios o foros orientados a la crítica de videojuegos hecho por influenciadores, aficionados, experimentados gamers o desarrolladores, además de las presentaciones que brindan sus creadores ${ }^{9}$.

9 En lo referente a ello existen una gran cantidad de espacios orientados a la critica a los videojuegos en la web, en particular a espacios como YouTube, entre ellos podremos mencionara. Eurogamerspain, Plano de Juego, 3D juegos, levelup, GameProTV, entre otros. 
Una vez realizado la inmersión y la selección inicial, nuestro siguiente paso es, la reducción selectiva de las fuentes y algunas especificaciones como, tipo de plataforma, consola de reproducción y el periodo histórico que abordan los juegos de video, siendo elegido el siglo XX, la etapa de gran despliegue bélico de nuestra historia de la civilización y de la cual la industria ha desarrollado muchos títulos, por su enorme rentabilidad. En este paso de selección fue de vital importancia información variada y virtual en espacios como YouTube, revistas de interés, opiniones de casas de videojuegos, entre otros. siendo anecdótico que algunos de ellos pude haber conocido e incluso jugado en alguna etapa de mi vida, pero nunca pensé en aquel momento utilizarlos para investigar. Esto genero un listado y experimentación inicial con ciertos títulos que continuación muestro, pero para motivos de esta investigación, solo nos concentramos en tres, que en líneas posteriores especificare el porqué de la delimitación.

La siguiente lista fue producto de nuestra búsqueda y selección de materiales, en ella se deseaba reunir un variado grupo de producciones, que puedan haber expresado un adecuado desarrollo de tramas, complejidad de abordaje, forma, ambientación, fotorealismo y reconstrucción histórica. Para saber cómo se observa el fenómeno de la guerra en el siglo XX, a través de los videojuegos. Este ingreso empírico es interesante, pues permite captar las diversas tramas, relatos y argumentos que desarrollaron estos videojuegos históricos. Y como mediante ello logran derribar la cuarta pared, generando una inmersión y reflexión, sobre el tema, pero no negamos, que la guerra en sí, tratada por los videojuegos, es también desarrollada como un gran espacio de competencia, disparos, destrucción, táctica, estratégica, en donde la distopía generaba el entretenimiento, esta lista es interesante a mi parecer, pues nos permite encontrar algunos detalles y elementos que a su vez evidencian una evolución de los juegos y su trama histórico bélica.

Debo dar una disculpa por que la lista no esté organizada cronológicamente, esta adecuada, a mi ingreso al tema, no obstante, bajo un criterio de clasificación acorde a la fuente, es decir al estilo u forma de jugabilidad, tomando en cuenta, además, la característica de realismo, dramatización u adaptación que desea mostrar la industria de los videojuegos con respecto a la guerra. A continuación, señalare los juegos, y sus peculiaridades, que han permitido una evolución e innovación: 


\begin{tabular}{|c|c|c|}
\hline En el nivel de estrategia, Táctica y logística & $\begin{array}{l}\text { El enfoque de la simulación en el manejo de } \\
\text { vehículos }\end{array}$ & $\begin{array}{l}\text { Los juegos de disparos o conocidos como } \\
\text { Shooters }\end{array}$ \\
\hline 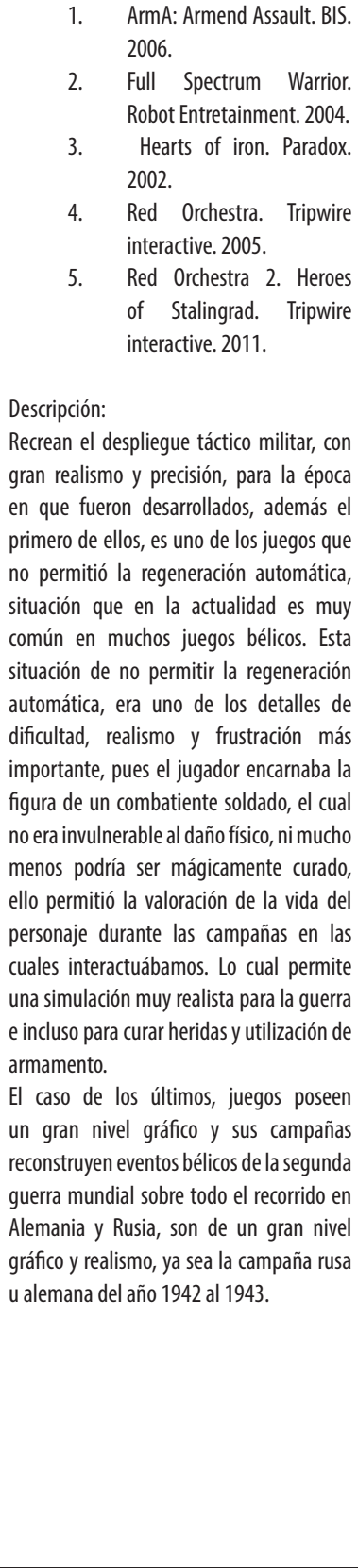 & 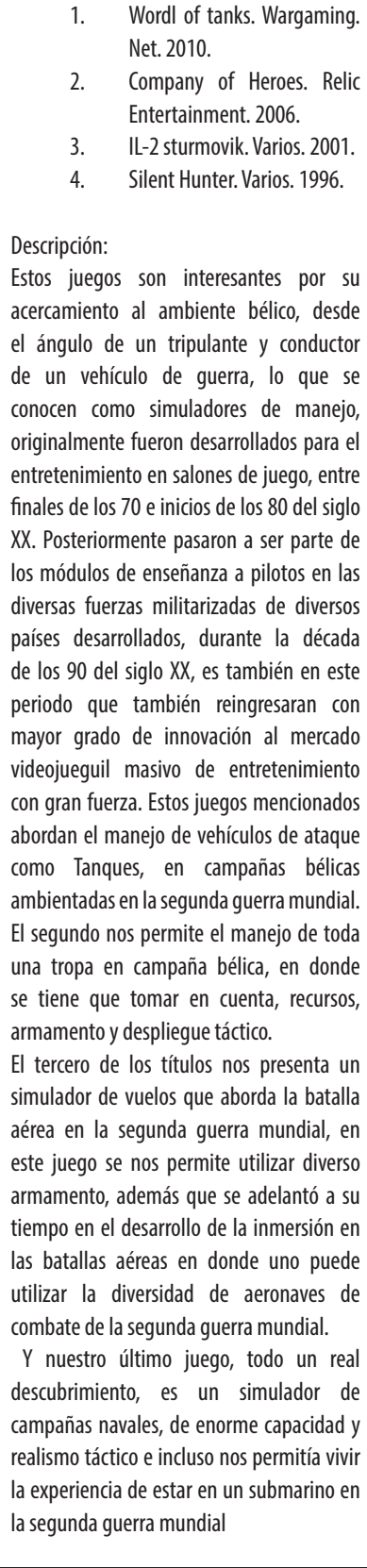 & 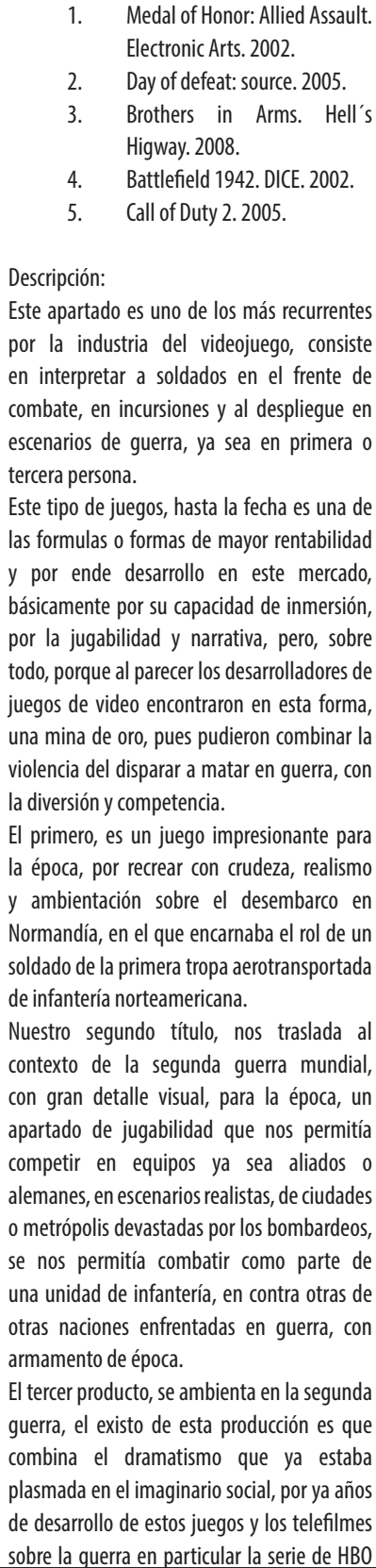 \\
\hline
\end{tabular}




\begin{tabular}{|c|c|c|}
\hline En el nivel de estrategia, Táctica y logística & $\begin{array}{l}\text { El enfoque de la simulación en el manejo de } \\
\text { vehículos }\end{array}$ & $\begin{array}{l}\text { Los juegos de disparos } 0 \text { conocidos como } \\
\text { Shooters }\end{array}$ \\
\hline & & 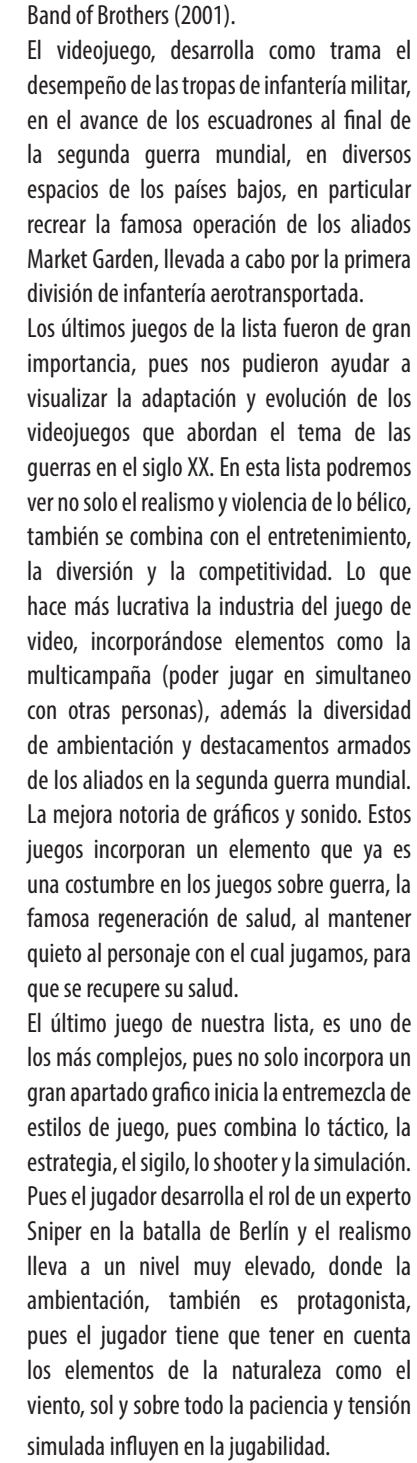 \\
\hline
\end{tabular}

El cuadro resumen, páginas anteriores, evidencia la búsqueda, inmersión y selección de videojuegos, que tienen como telón de fondo las guerras. Y en particular los conflictos bélicos más impactantes en el siglo XX, siendo la más adaptada, la Segunda Guerra Mundial. Esta primera selección, nos dio la oportunidad de conocer como desplegar y ensayar una investigación con este tipo de fuentes. En donde los problemas para financiamiento, desinterés intelectual, no se hicieron esperar, pero con el tiempo fue mejorando, pues la investigación fue asumida personalmente y con gran apoyo de paciencia de mi familia y amistades. 
Este tipo de fuente al igual que otras, demanda horas de inmersión para la investigación histórica, sumergirnos en ellas y experimentar, es decir jugar, es parte de esta labor. Lo que hace tal vez, ver con cierto recelo a este tipo de estudios. Otro punto en resaltar, es la gran inversión económica, pues muchos de estos juegos estaban orientados a diversos tipos de plataforma, debemos considerar que cada juego de video tiene un costo en promedio de 70 a 80 dólares, las plataformas tienen un costo de 400 a 500 dólares, tomando en cuenta membresías en línea y costos adicionales que fluctúan entre 50 a 100 dólares anuales. Situación que se tienen que considerar al desarrollar este tipo de trabajos intelectuales, debemos considerar que la industria del juego de video esta en muchos espacios, pero dividida, pues no todos están orientados para la PC, también son algunos exclusivos para consolas como Xbox y Play Station en sus diversos modelos.

La mejor sugerencia es una selección delimitada y ello garantiza un buen presupuesto, pero limita la exploración inicial, lo cual nos permitió conocer los diversos estilos, innovaciones, adecuaciones y terrenos que abordaron la industria de videojuegos al desarrollar y explotar el tema de la guerra en el siglo $\mathrm{XX}$, además de mostrarnos, la predilección por parte de estas empresas, al conflicto bélico que afecto a más de 60 millones de personas en el mundo, La Segunda Guerra Mundial, uno de los momentos de mayor brutalidad y violencia desarrollada entre los años 1939 a 1945. Esta primera exploración nos permite experimentar errores y alcances de la investigación, debo incluir que también es necesario ampliar nuestra incorporación de fuentes complementarias como; foros en línea, canales informativos de YouTube, libros especializados y publicaciones empresariales tanto en revistas físicas como digitales.

Esta selección nos permitió identificar tres videojuegos de reciente entrega, que son el material clave de esta investigación, para lo cual pudimos desarrollar un instrumento, para evaluar hasta la fecha a 100 jugadores, brindándonos sus apreciaciones y de saber cuánto influencian en la construcción del imaginario de la sociedad con respecto al tema de la guerra y su connotación histórica. Además, nos permitió un acercamiento a fuentes audiovisuales de YouTube y foros de comunidades de juego como AMINO, un espacio interactivo virtual en el cual individuos con intereses en común, comparten opiniones y comentarios sobre sus experiencias, como es el caso de los videojuegos históricos sobre la guerra.

Como agregue paginas anteriores, el análisis de este ensayo se centró finalmente, en tres videojuegos, desarrollados para la plataforma Play Station 4 de la empresa Sony (PS4), estos juegos son hasta la fecha la síntesis de diversas innovaciones tecnológicas e informáticas, a su vez es de nutrida en; narrativa, trama, fotorealismo, jugabilidad. Pero sobre todo en base histórica ambientada a las guerras en el siglo XX. Además de generar el abordaje reflexivo al tema de la guerra en forma cruda, violenta, con un despliegue argumentativo narrativo de inmersión, en los cuales se nota el esmero de los desarrolladores de la industria de los videojuegos, por brindar a los usuarios una experiencia de juego, que nos muestre la guerra en su desarrollo. Pero no debemos creer que ello es su único fin, seriamos ciegos el negar que un videojuego, está hecho en su mayoría para 
entretener y generar enormes ganancias económicas para las empresas, entonces podemos argumentar que la experiencia en estos tres juegos es compartida entre la diversión y el adentrarnos en la piel de la actividad bélica, ya sea en la piel de un soldado, compartiendo historias de guerra, utilizando diversos medios o vehículos, desarrollando mecánicas de misiones y como supervivencia al terror, la violencia y lo inevitable de la guerra la muerte. Elementos que, combinado con lo narrativo, nos permiten no solo identificar a buenos o malos en las guerras, 0 tomar un bando u otro. Algo que podremos agregar es que estos juegos logran derribar con sus argumentos la cuarta pared, e identificar al principal enemigo en estos momentos históricos, el fenómeno de la guerra.

Esta investigación nos permitió comprender, que el $82 \%$ de los opinantes sometidos a nuestras interrogantes e instrumentos, observan al fenómeno de la guerra con gran crudeza, pero sobre todo saben distinguir, la ficción y el entretenimiento de lo real de las guerras en el siglo XX. el 67 \% se informó sobre las guerras que narran los videojuegos gracias a su exploración en los mismo, es decir, estas producciones estimularon la búsqueda de información histórica en otros soportes, ya sean estas visuales o escritas. Situación a tomar en cuenta, pues al parecer, para estas nuevas generaciones, el motivador para buscar información sobre acontecimientos $u$ estimular a ello son las producciones audiovisuales, situación a la que no escapan los videojuegos. Tal como lo ha podido hacer la literatura narrativa y de entretenimiento, las memorias, las fotonovelas, comics, filmes, los documentales, series animadas, series televisivas y hoy los juegos de video.

Sobre este punto sería interesante ver en el tiempo, estudios de mayor madurez, que aborden el tema de la enseñanza de historia complementada con el uso de videojuegos, que debemos saber guiar y en la cual los historiadores debemos integrar con el tiempo, más aún cuando la memoria histórica está depositada en este tipo experiencias. Y por sobre todo que en la actualidad adecuar estos temas, toma en cuenta no solo estudios u opiniones de historiadores para su elaboración, además complementa el testimonio de los sobrevivientes a los conflictos bélicos del siglo XX, o relatos de los mismos que ya están desapareciendo. Siendo estos formatos nuevos soportes para el rescate, al menos parcial, de la memoria, de los acontecimientos $u$ hechos históricos, siendo estos soportes nuevos medios para el acercamiento a nuevas generaciones a lo irracional, complejo y discutible que es la guerra bajo el velo del entretenimiento.

Estos tres juegos son: Battlefield 1, DICE y Electronic Arts. 2016, este juego de video explora con sus campañas uno de los momentos históricos, menos explotados por las empresas de videojuegos, pero que históricamente causo un gran impacto, a inicios del siglo XX, la llamada Gran Guerra, La Primera Guerra Mundial, conflicto de gran impacto en la historia de la civilización, cuyo desarrollo abarca de 1914 a 1918. Este juego más allá de mostrar un gran desarrollo grafico visual, foto realista y tecnológico, nos entrega modos historia, con diversos estilos o formas de juego, armas y vehículos, en donde nos permite ingresar, a parte de la vida de los protagonistas, a través de sus historias de un individuo en el campo de batalla, se dan los acercamientos a la desgracia que es guerra. El 
inicio es impactante, el prólogo del videojuego nos enseña como jugaremos, en esta historia y como si nos equivocamos moriremos, pues desde ya el juego nos menciona algo que es importante en una guerra, es que en el campo de batalla la posibilidad de sobrevivencia es equivalente a la muerte. Es decir, en el inicio del juego se retira la opción de revivir. En esta etapa de inicio encarnamos, al soldado de un destacamento, que al morir el personaje, pasa otro escenario ocupando, el puesto de otro soldado sobreviviente, generando un efecto frustrante en el jugador. Este juego de video, desarrolla un apartado narrativo y de despliegue técnico cinemático, foto realista y sonoro impresionante, nos adentran al primer nivel y al realismo de la primera guerra mundial, un panorama de muerte, desesperación y caos.

Encarnamos, en el prólogo u nivel inicial del juego, al soldado afroamericano descansando, el cual recuerda su participación en la guerra, escuchando como música de fondo: Dream a little dream of me. Es así como inicia Battelfield 1, el cual como menciona, "está basado en eventos que ocurrieron hace más de cien años. Donde más de 60 millones de soldados lucharon en "La guerra que acabaría todas las guerras". Pero no acabó con nada. Fue una guerra que cambió el mundo para siempre"10. Lo que sigue es el combate en el frente. Y con la frase "Nadie espera que sobrevivas". Inicia el juego de su historia, la jugabilidad es en primera persona en donde representas a Simón Edward 1885-1918, un soldado de infantería en un escenario desolador y destrozado por la guerra, acompañado de diversos sonidos de fondo entre órdenes, voces ininteligibles, pisadas, disparos y bombas, que buscan aturdir desde el inicio haciendo una inmersión efectiva hacia el juego. En donde cada avance nos entrega una frase diferente, como: "Vinimos de todas partes del mundo. Muchos de nosotros pensábamos que esta guerra sería nuestro rito de paso, nuestra gran aventura. Déjenme decirles, no fue ninguna aventura." Durante la campaña el juego es muy difícil, en todo los sentidos, muchos enemigos disparando desde todas direcciones, el ruido, el armamento lento y si cometemos errores, nuestro personaje es abatido en el frente de combate, ante la espera de reaparecer en el escenario con el mismo personaje, nos damos con la sorpresa frustrante, (situación que el 100\% de jugadores expreso sobre el juego del prólogo), de que nuestro personaje no revive y muere, el juego continua y seguimos en el mismo escenario, pero con otro personaje Harold Perry 1898-1918, este recurso técnico sorprendió a cada jugador que experimento el videojuego pues esperaba que el personaje se regenere, a muchos les impacto pues experimentaron la muerte del personaje, sin posibilidad de revivirlo, ya en el rol del nuevo personaje continuamos con la travesía y con una breve recomendación, pasamos a representar un soldado en trinchera que maneja una ametralladora, luego cae y toma una escopeta con la que avanza derribando a soldados enemigos, hasta que cae en llamas por fuego enemigo. $Y$ nuevamente experimentamos la muerte del personaje y su obituario en nuestras pantallas, con la frase que continua "Las nuevas máquinas mortíferas, como el tanque, podían a veces cambiar el campo de batalla de un día a

10 Frase de inicio del prologo de jugabilidad. "Una incursión desesperada de los alemanes amenaza la posición que protege el $369^{\circ}$ regimiento de infantería de EUA, los" Harlem Hellfighters" 1.0 Amanecer "Maldita sea, vamos" Battlefield 1. DICE_Electronic Arts. 2016. 
otro. Por suerte, casi todas estaban de nuestro lado. Casi todas." Reaparecemos en el escenario en otro lado del frente de batalla, esta vez representas un soldado dentro de un tanque, Chad Carrington 1886-1918 desplazándose y manejando la ametralladora del vehículo en apoyo a la infantería, aportándote la sensación de avance de la tropa, hasta que finalmente explota el vehículo y muere nuestro personaje y continua la frase. "En vez de aventura hallamos miedo, y lo único que nos hace iguales a todos en la guerra es la muerte". Pasamos a encarnar a los soldados de infantería Lloyd Simpson 1892-1918 y Frank Rapides 1888-1918 quienes en base a disparos y granadas van haciéndose paso entre los escombros y ofensiva enemiga, hasta que, igual que los anteriores mueren, abatidos por fuego enemigo, se nos muestra su obituario. Y la frase continua de la mano de una cinemática y banda sonora inmersiva. "Si presionan, presionamos. De vez en cuando, presionamos tanto que la luz se cuela entre las nubes y el mundo fuera de la guerra brilla, pero fuera de nuestro alcance. La guerra es el mundo y el mundo es la guerra. Pero detrás de cada mira hay un ser humano. Nosotros somos esas personas. Somos los hartos y los inocentes. Los honorables y los criminales. Somos los obligados a ser leyenda y los olvidados en la historia. Somos los caballeros del cielo, los fantasmas del desierto y las ratas en el lodo. Estas son nuestras historias". Así nos presenta su inicio este juego, que en sus diversas fases, en su modo historia nos va a ir atrapando, gracias a su despliegue visual, sonoro, sus narrativas y diálogos, tal como lo plantea, Delgado, 2012, pp.63-77 y Salas, 2016, pp. 201-206 ${ }^{11}$ de profunda reflexión. Nos hará asumir el rol de los protagonistas con los que debemos jugar, con la cuota de reflexión y entretenimiento, que permite la jugabilidad virtual, con campañas en diversos escenarios y armamentos de la primera guerra mundial, además que los apoyos de maquinaria bélica impresionante de gran capacidad destructiva desarrollada por aquellas épocas, donde el mundo de la segunda etapa de la revolución industrial, construía; dirigibles, aviones, grandes trenes blindados, acorazados en el mar, entre otros. Lo cual nos permite apreciar el desarrollo industrial orientado a la destrucción y comprender lo violento de la conquista geopolítica generada por los imperios en La Gran Guerra.

Debemos destacar que las animaciones recrean momentos históricos con cinemáticas de batallas reales de la primera guerra mundial y recreaciones de soldados que están en estos lugares de enfrentamiento, recordando sus momentos antes de estar en la guerra y mediante ellos participamos de sus triunfos y desgracias ya en el interior del conflicto. El fotorealismo y la banda sonora contribuyen en un mejor efecto de inmersión del jugador, además del doblaje a múltiples idiomas que favorece a la experimentación del jugador de diversas naciones. Existen también algunos elementos anecdóticos que crearan en el usuario algunos niveles de comprensión y reflexión para comprender la importancia de los medios de comunicación de inicios del siglo pasado, como los caballos, los trenes, los telégrafos y las famosas palomas mensajeras que servían para ordenar el apoyo y ataques a secciones en el campo de batalla.

11 Véase, Delgado Ponce, ÁGUEDA. Los Videojuegos trasladados al cine: análisis y caracterización de la narrativa audiovisual en ambos medios. Revista Comunicación, N 10, vol. 1, años 2012. 63 -77. / Salas Sabal, ISRAEL. La Narrativa cinematográfica en los videojuegos. Cataluña. Universitat Oberta de Catalunya. 2015 - 2016. Págs. 201 - 216. En estos textos se plantea la importancia de la narrativa y lo discursivo en el desarrollo argumentativo e inmersivo de los videojuegos. 
Al finalizar el juego nos muestran los desarrolladores un epilogo dedicado a los jugadores que encarnaron a los que pelearon esta guerra y cuya cinemática final tiene como objetivo honrar, respetar, comprender y reflexionar lo que vivieron, con este discurso: "Hoy lucharemos" Un día todo esto se acabará. Un bando u otro vencerá, aparecerá la guerra que dará fin a todas las guerras. Las armas se oxidarán, el pasto crecerá y no quedará nada de esto. La tierra sanará sola. Todo acaba sanando sólo. Pará entonces, hará mucho que nos habremos ido pero, quizá, no habremos sido olvidados. Si la historia recuerda sólo a uno de cada mil de nosotros entonces el futuro estará lleno de historias de quienes éramos y lo que hicimos. De cómo vivimos, cómo luchamos y cómo morimos. Cuando todo esto termine y se haya ganado la guerra, nos recordarán. Pero hasta que ese día llegue, resistiremos, miraremos a la muerte a los ojos y ilucharemos! ${ }^{12}$.

Nuestro segundo videojuego es: Call of duty: World War II. Activision Sledgehammer gamess. 2017. Este recrea parte de las campañas de la segunda guerra mundial y en particular la labor de soldados norteamericanos en el conflicto bélico más cruel de la historia. En el cual encarnamos el papel del soldado Daniels que participa del desembarco en Normandía, el llamado día $D$ y realiza todo un recorrido de 11 diversos escenarios, que recorren desde las costas de Normandía hasta las riveras del Rin en Alemania ${ }^{13}$. Este modo historia que desarrollamos nos acerca al desempeño del soldado, que en todo momento pone a prueba sus límites y pone en práctica el deber en el campo de batalla, es mediante este soldado norteamericano de la primera división en infantería, nos adentramos a este escenario donde la táctica de guerra, nuestro desempeño de tropas y nuestras habilidades en combate, podrán hacer frente a uno de

12 Frase del epilogo dedicado a los jugadores y a los que lucharon en esa guerra. "Hoy Lucharemos" Battlefield 1. DICE_Electronic Arts. 2016

13 Este recorrido en generalidades posee una fidelidad histórica, combinada con una distopía argumentativa, sobre el avance aliado norteamericano a finales de la segunda guerra mundial, que a continuación señalare: 1. Día D. Playa de Omaha, Francia 6 junio de 1944. Estamos invadiendo Norma día para arrebatarle Francia a los nazis. 2.Operación Cobra. Caen Francia 25 de julio de 1944. Informe de misión. Pasaron siete semanas desde el día D. Avanzamos tierra adentro para salir de Norma día y asegurar Marigny. Así lograremos controlar los caminos y atravesar Francia hasta llegar a París. La liberación está cerca. 3. Fortaleza. Marigny, Francia. 26 Julio de 1044. Informe de misión. 26 de julio. Nos refugiados en una granja a las afueras de Marigny. Cierro los ojos y pienso en Hazel, pero siempre acabo teniendo el mismo sueño. 4. Doe. Falais, Francia. 20 de agosto de 1944 Informe de misión. Durante un mes, hemos seguido de cerca de los últimos kartoffel que lograron escapar. Pero lucharán hasta el final, igual que una serpiente arrinconada. 5. Liberación. París, Francia. 25 de agosto de 1944. Informe de misión. Agosto. 1944. Llegó el momento. Vamos a liberar París. Los franceses y los estadounidenses llegaran al amanecer, lo que significa que nos desplazaremos esta misma noche. 6. Daño colateral. Aquisgran, Alemania. 18 de octubre de 1944. Informe de misión. Octubre. Estamos en Aquisgran. Los kartoffel luchan con uñas y dientes después de que los aliados invadieron uno de sus bastiones por primera vez. Aunque no será la última. 7. Carnicería. Hürtgen, Alemania. 14 de noviembre de 1944. Informe de misión. Nada volverá a ser lo mismo después de Aquisgran, aunque por fin logramos entrar en Alemania. El pasaje hacia el Rin está abierto y ya no hay marcha atrás, para nadie. 8. Colina 493. Colina de Hürtgen, Alemania. 14 de noviembre de 1944. Informe de misión. Sigo esperando a Pierson. Es un ser imprevisible y su historial no es lo que se dice destacable. Paúl, si estuvieras aquí, se que lo pondrías en su lugar. Espero que Zussman y Aielloresistan hasta que nos reunamos con ellos. 9. Batalla de las Arenas. Arenas, Bélgica. 25 de diciembre de 1944. Informe de misión. Pasaron seis semanas desde que mataron a Turney y a mi me ascendieron. Es navidad. Estamos en el bosque de las Arenas, Bélgica. Hace un frío insoportable. Será un combate de mil demonios. 10. Emboscada. Ardenas, Belgica. 27 de diciembre de 1944. Informe de misión. Pierson se está hundiendo en un delirio, y siento que me está arrastrando con el. Tengo que estar alerta si quiero sobrevivir. 11. El Rin. Remagen, Alemania. 7 de marzo de 1945. Junto a la división 99 y la $9^{\circ}$ Blindada debemos tomar el puente de Remagen. Debemos cruzarlo para acabar con la resistencia alemana. 
los conflictos más crueles de la historia, la Segunda Guerra Mundial. Desde el principio nos plantean la crudeza del conflicto y las campañas conflicto no cesa la violencia, haciendo sentir que el avance de la infantería norteamericana aliada, es dificultoso por la resistencia alemana, la crudeza del territorio y la mejora de la respuesta de la inteligencia artificial, que nos hace sentir ello, la resistencia aliada, en donde se destaca la labor de Norteamérica en la guerra.

El juego toma en cuenta la recreación de la segunda guerra mundial por las razones personales de los directores de los estudios productores y además del interés industrial por recrear un momento histórico de gran rentabilidad en los negocios de este rubro. Es la búsqueda de la fidelidad histórica ${ }^{14}$ y el rescate de la memoria de los combatientes, veteranos que a la fecha, ya son muy pocos los que sobreviven. Esta distopía videojueguil, envuelta en hechos reales, busca comprender y dejar en alto el lema, "la llamada al deber" en donde cada misión se puede ver ello mediante su recorrido en las ambientaciones y entornos cinematográficos de gran despliegue, este juego al igual, otros nos distinguen al enemigo, que son las tropas alemanas en el conflicto, pero también de mostrarnos que ellos son el bando opuesto en un escenario infernal llamado la guerra.

Este juego también cuenta con un despliegue discursivo muy intenso que, complementado con la banda sonora, la cinemática y demás efectos, nos permite comprender la magnitud de lo que vamos a experimentar, en el rol de un soldado a inicios del histórico día $D$. tal como lo muestra la instrucción al juego, en donde la pantalla nos muestra las siguientes frases: "Participaron más de 50 países, causó 65 millones de víctimas, es el conflicto más mortífero de la historia." A ello se suman el despliego cinematográfico del ejército alemán y el narrador de una radio Informa que: "Europa occidental se encuentra al borde del abismo tras los feroces ataques de la maquinaria de guerra de Hitler. En estos aciagos momentos debemos armarnos de valor para ser el baluarte contra la opresión. La arremetida de los nazis es la mayor prueba a la que nos enfrentaremos, pero junto a nuestros aliados, lucharemos y los derrotamos." A continuación, se visualiza diversos escenarios entre los que destaca el enrolamiento de los soldados y la formación de tropas norteamericanas listas para combatir en el frente, mientras se escucha el discurso del presidente Roosevelt:" Este dia acometemos una poderosa misión. Lucharemos por salvar a nuestra civilización y liberar a la humanidad. Nuestros hijos, orgullo de nuestra nación. Guíenlos con firmeza y lealtad. Su camino será largo y duro. Las almas se estremecerán con la violencia de la guerra, en esta hora de gran sacrificio, prevaleceremos". Es así como iniciamos con el recorrido con el soldado Daniels, que momentos de descanso con sus camaradas, previo a la incursión narra y comenta su situación, sueños y aspiraciones de sus compañeros, que nos acompañaran en nuestro bélico recorrido, en cual desde el inicio nos muestra la crueldad, el terror de un campo de batalla y la crudeza del desembarco en Normandía, que es el inicio de la misión, realmente una recreación, violenta , dramática y aterradora del avanzada de los aliados en la captura de la playa, decenas de muertos, ruido de disparos, explosiones, Ilanto, gritos desgarradores y gritos de furia, desesperación, generan

14 Para ello véase el documental con referente a la creación del videojuego https://www.youtube.com/ watch?v=0ffKKIhCVB8\&feature=youtu.be 
en el jugador un experiencia de ingreso a la crueldad y de desconcierto, tal como el $100 \%$ dan como respuesta, pues en esta primera parte, si no fuese por la guía de metraje de orientación de avance, los jugadores estarían desorientados, tal como el $90 \%$ afirman. Este inicio marca en todo momento el nombre del juego y el lema de la producción el deber y los deseos son puestos a prueba ante la adversidad, desgracia y en el infierno de lo que significa la guerra.

Nuestro tercer juego desarrollado en el año 2014 y que hasta la actualidad se sigue actualizando es: This War of mine. 11 bits Studios. 2014. Es uno de los títulos de mayor controversia, por como aborda el tema de la guerra, pues a diferencia de los títulos anteriores en los que encarnamos el papel de un soldado u algún militar o personaje armado de turno, que puede combatir en la guerra, en forma plana sin alterar el desarrollo de los hechos históricos ${ }^{15}$, Aunque en el caso de uno de ellos, (Call of Duty) nos entregan una subtrama mitopoyética, fuera de la campaña de la segunda guerra mundial, en la cual descubre los experimentos alemanes de armas biológicas y se combate contra Zombis, que ya es un agregado desbordado de recreación con la intención, de que los jugadores destruyan todo a su paso, sin mayores cuestionamientos morales, tomando en cuenta que el atractivo de la industria de los videojuegos.

Situación que no contempla nuestro tercer videojuego, el cual no está ambientado dentro de alguna guerra mundial, pero que, en si puede ser la recreación de muchas, en cuanto a que se encarna a los sobrevivientes, a ciudadanos, que no son soldados, los civiles, el llamado daño colateral. Desarrollamos el rol de un o una, según lo que se elija, sobreviviente en una guerra, el cual debe supervivir en ese escenario, utilizando diversos medios como; alianzas, robos, búsqueda de restos, engaño, sigilo, astucia y que pueden incluso romper o desafían, situación que pondrá al límite e incluso quebrar sus principios éticos y morales, que en una sociedad tiene como pilares. Pero que en guerra se resquebrajan o son tan frágiles en mantener, este acercamiento atemporal nos permite ingresar al terreno de la guerra y hacernos reflexionar y cuestionar nuestras acciones desde un ámbito moral y racional, del superviviente. Este videojuego es realmente un gran planteamiento, puesto sobre la práctica, una obra de arte que desafía y cuestiona nuestras decisiones, que nos presiona en la jugabilidad, llevando a cuestionar nuestras decisiones y lo complejo de la guerra en circunstancias adversas $y$ tal vez.

Este tipo de juego es catalogado, por la opinión de miles de jugadores en redes, como un adiestramiento, entrenamiento o cuestionamiento de lo que puede pasar en una guerra y lo que podríamos estar enfrentados a vivir, si no somos los soldados y héroes, solo somos el común de ciudadanos víctimas de un conflicto bélico, en el cual debemos encontrar la forma de vivir mientras dure el conflicto

15 Situación que muchos de los jugadores critica, en nuestro instrumento de recopilación, pues siente que el juego debe ser libre para poder generar su propia historia, una situación que los desarrolladores de videojuegos no han permitido, desean crear sus productos ambientados en estos hechos históricos, que proporcionen una experiencia de información acorde los mismos hechos históricos, encarnado roles de soldados en el campo de batalla, para no dejar espacio a creaciones ahistóricas, que podrían generar confusión. Encuesta en línea utilizando, Amino apps, foro sobre: videojuegos de Guerra, mayo 2019 (instrumento personal desarrollado para esta investigación 
o simplemente aprendamos a sobrevivir en base a nuestras decisiones. En un mundo devastado, en donde la incertidumbre de no saber cuándo u cómo, se recupera o no el orden institucional y estatus quo de una sociedad o un mundo devastado por la guerra.

\section{ALGUNAS REFLEXIONES FINALES}

Para finalizar, estas páginas de investigación, expuestas en forma de ensayo descriptivo, parecería inicialmente una narración o resumen, sobre como investigar u observar a los videojuegos, además de referir la trama u historia que abordan los videojuegos. Sí al leer estas páginas, ello ha parecido, la intensión no solo era el abordaje de esos elementos. debemos también rescatar que nuestra investigación a pesar de estar en inicios, nos ayuda a observar ciertas luces, mostrando el uso de nuevas fuentes y como podremos apreciarlas en espacios virtuales, además del reto al contemplar o concurrir a nuevos sitios de interés y el desarrollo de instrumentos recopilatorios de información, nos brindan la posibilidad de comprender lo que hacen nuestras creaciones sociales, que no solo pueden entretener. También generan usos alternos y la utilidad que podremos encontrar a estas creaciones sociales, que en nuestra opinión preliminar se han convertido en nuevas formas de retratar parcialmente los eventos y la difusión de hechos o sucesos mediante la recreación del videojuego, que sean de complemento parcial a lo que hacemos los historiadores.

Pero también nos permite percatarnos que no todos son apreciados por los usuarios por su rigor histórico a pesar de que muchos de ellos tomen los mejores cuidados para realizar sus recreaciones, el rigor histórico, es un dilema, pues la diversión puede en algunos casos, cambiar dicho elemento y distorsionar la historia, pero un gran aporte es que algunos videojuegos, como los apreciados, nos pueden ayudar a graficar las campañas bélicas, y otorgarle ficción narrativa , basada en relatos de los ideales, dilemas y cuestionamientos que el espíritu humano constituyo con las guerras. Todo ello mediante las narrativas complejas de las historias de los personajes, ya sean ellos reales o no, que se encarnan. Lo cual muestra que los videojuegos pueden contribuir con el aprendizaje y la comprensión de algunos puntos o problemas que aborda la historia narrativa, que se desarrolla en la trama u dinámica de este tipo de videojuegos, es decir posee una buena historia.

Debemos recalcar que el videojuego en los últimos años, por el cuidado en su elaboración, en la recreación sobre los temas de la guerra, se han convertido en complementos de información por su influencia generacional, por la nostalgia o interés por el pasado.Y que, gracias a la reconstrucción dinámica de su naturaleza, nos informan, estimulan a la enseñanza, muy aparte de entretener. Pues recrean parte de acontecimiento o fenómenos de nuestra cultura o civilización, que encuentra en la guerra, no solo una huella de dolor y sufrimiento, también encuentra una cuota morbosa de entretenimiento y diversión 
Este trabajo también nos muestra lo paradójico y los complejos caminos que toma la información histórica, que, al trasladarse a otros soportes, en el caso del videojuego, puede motivar la reflexión y reproducción social de información y por ende memoria. Mostrando una expresión social, de enorme desarrollo y utilidad social, entre otros fines. Los videojuegos son un producto social, que retroalimentan a una gran cantidad de la población de nuestra sociedad, la cual ha ido incrementando en el tiempo desde su aparición para los años 50 , hasta su popularización en la década de los 70 y con mucho énfasis en la actualidad, ello nos hace pensar, que el consumo de estos, ha hecho posible insertar a estas creaciones en nuestra vida cotidiana y que mediante ello influya en nuestra forma de apreciar eventos históricos recreados complementados, a través de lo es fantástico e irreal, sucesos históricos de enorme impacto en la civilización. Pues ellos generan una apreciación sobre la realidad, mediante una construcción fantástica inspirada en lo social, lo cual permite al usuario de los videojuegos ingresar y adecuarse a la maniobrabilidad, este mundo recreado.

Pero, ¿cómo está inmersión puede ser útil para nuestro trabajo como historiadores? Una respuesta ampliamente debatible y cuestionable, pero sobre todo necesaria, pues en principio toda reflexión en torno a un constructo social, que impacta en forma constante, en nuestra sociedad, es razonablemente importante. En segundo lugar, estas entidades despliegan una serie de elementos que influyen en la sociedad generando múltiples opiniones. Tercero, es la utilidad social que se ha ido identificando y constituyendo en el tiempo, sin dejar de lado todo el cuestionamiento y problemática que se ha podido generar o constituir en torno a ellos. El cuarto punto, es que estas creaciones son vehículos o medios que transmiten diversas expresiones sociales, con cierto grado de distorsión, que versan e intervienen en la construcción de nuestro imaginario y el de otras generaciones a las cuales influencia, sobre la sociedad. Una quinta situación, es que nos permite innovar en nuestra labor, pues hace posible incorporar una nueva fuente para estudiar a la sociedad, desarrollar metodología para su estudio, análisis y reflexión.

$\underline{\text { Sexto, }}$ nos permiten constituir una serie de basamentos teóricos, filosóficos, metodológicos, técnicos y de análisis historiográficos, que nos otorguen nuevas ideas sobre estos elementos sociales y realizar un ingreso a un universo, creado y fantástico, que puede en ocasiones recrear la realidad presente o pasada, lo cual activa mecanismos complejos en la red neuronal que permite una asimilación y sobre todo inmersión a este mundo que los desarrolladores nos entregan para la interacción. Debemos tomar en cuenta que esas realidades recreadas son de diversos tipos y orientadas a diversas edades, aunque para el caso de nuestras tierras, ello no sería el patrón que influye en la adquisición, ello corroborado por el instrumento de recopilación de información.

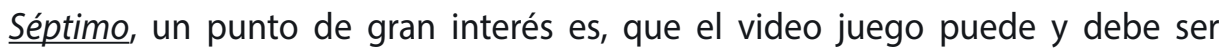
considerado como un recipiente de información o fuente para la investigación, que debe de ser observado hermenéuticamente, pues se puede comprender la intensidad y capacidad de la información que puede conectar a las generaciones 
o influenciarlas, decodificar discursos o retoricas, además de entender como ellas activan o retroalimentan la sensibilidad, la mentalidad y la memoria social. Y que gracias a la historia se le puede utilizar metodológicamente e integrar en múltiples investigaciones, por su origen, creación e influencia y pues en el tiempo se está convirtiendo en una fuente que alberga retazos de información social sensible, la cual encuentra múltiples formas para no dejar en el olvido diversos momentos históricos, ubicados en diversos periodos.

Finalmente debo de añadir, una idea que será motivo de otras páginas, es el hecho de que los videojuegos también expresan actitudes históricas, no solo de relato, sino de postura al relatar sobre los hechos, pues recordemos que la gran mayoría de los juegos de video que abordan la guerra, lo hacen bajo la visión de los vencedores pues recordemos que mayoritariamente la historia la hacen y divulgan, bajo este ángulo, aunque cierto número de empresas han desarrollado juegos ucronicos u ahistóricos en donde la distopía es la alteración de la historia, creando reflexión e incluso escenarios realmente macabros, como el caso de juegos que plantean que la II guerra mundial, la gano Alemania, que una resistencia tiene varias décadas y que el mundo absolutista constituido, es un espacio desbordante de limitaciones sociales, resaltando con ello en forma antagónica los beneficios de una historia como la conocemos.

Para cerrar estas páginas, creo que la historia, en este preliminar ingreso a delimitado y orientado algunas ideas principales, como dilemas $u$ opciones al investigar, en el relato de la investigación, situación nos da mucho aliento, pues es solo cuestión de tiempo para que múltiples investigaciones ganen su espacio en el terreno de la labor historiográfica, pues no hay que olvidar que todo aquello que es parte $u$ afecta al hombre como ser social, es motivo de observación, análisis y reflexión para el historiador.

\section{BILIOGRAFÍA}

Botermans, JACK., Burrett, TONY., Van Delft, PIETER., Van Splunteren, CARLA. El Libro de los Juegos. Historia y origen de los Juegos. España. Editorial P\&J. 1987.

Bourdieu, PIERRE. Sobre la Televisión. Barcelona. Anagrama. 1996.

De La Cruz Villanueva, CARLOS A. "El Perú en el mundo de los videojuegos" Ponencia. IX Seminario Visiones del Perú. El Perú en el mundo. Universidad Ricardo Palma. Lima. Noviembre 2019.

De La Cruz Villanueva, CARLOS A. Los videojuegos y su influencia en la percepción histórica sobre las guerras del siglo XX. (Ponencia). VII Encuentro de jóvenes investigadoras e investigadores de historia contemporánea. Mesa-Taller 14. Nuevas narrativas contemporáneas sobre la historia: Cine, televisión y videojuegos. España. Universidad de Granada. 2019.

https://blogs.ugr.es/jovenesinvestigadores/wp-content/uploads/sites/46/2019/08/ DE-LA-CRUZ-VILLANUEVA-Carlos-A..pdf 
Delgado Ponce, ÁGUEDA. Los Videojuegos trasladados al cine: análisis y caracterización de la narrativa audiovisual en ambos medios. Revista Comunicación, N 10, vol. 1, años 2012.63-77.

Ferro, MARC. El cine. Una visión de la Historia. España. Akal. 2008.

Huizinga, JOHAN. Homo Ludens. España. Alianza Editorial. 2007 (1938).

Kent, STEVEN L., La Gran Historia de los Video Juegos. Nova. 2011.

Lebihan, YANN. La historia de los Videojuegos. España. Ma Non Tropo. 2018.

Salas Sabal, ISRAEL. La Narrativa cinematográfica en los videojuegos. Cataluña. Universitat Oberta de Catalunya. 2015 - 2016.

\section{Canales de YouTube}

Plano de Juego. Canal orientado al análisis y game disign.

https://www.youtube.com/channel/UC910yxBmXzGDH_2cx0XEOXw

Eurogamer, Información y entretenimiento

https://www.youtube.com/user/eurogamerspain

3D juegos.com

https://www.youtube.com/user/3DJuegosTV

TEC. Canal de contenido de noticias y comentarios sobre innovación tecnológica. https://www.youtube.com/channel/UCBtSfnUVAuq9fKaPrMWa_ag

Phillip Chu Joy. Canal de Contenido tecnológico

https://www.youtube.com/channel/UCym16Z6ocsTe85tz91eyl4w

Documentales Gameplay.

https://www.youtube.com/watch?v=fdzizl3MEUs\&t=4576s /

TED. María Lujan Oulton ¿Por qué son obras de arte los videojuegos?

https://www.youtube.com/watch?v=IO6X1nZuAOc\&t=46shttps://www. youtube.com/watch?v=rAbpF6XqIAM

TED. Daphne Bavelier. El cerebro bajo la influencia de los videojuegos.

https://www.youtube.com/watch?v=e_pYROUysDM

Official Call of Duty ${ }^{\otimes}$ : WWII - 'Brotherhood of Heroes' Documentary https://www.youtube.com/watch?v=0ffKKIhCVB8\&feature=youtu.be 